\title{
Automated objective classification of daily circulation patterns for precipitation and temperature downscaling based on optimized fuzzy rules
}

\author{
András Bárdossy ${ }^{1, *}$, Jiri Stehlík ${ }^{2}$, Hans-Joachim Caspary ${ }^{3}$ \\ ${ }^{1}$ Institute of Hydraulic Engineering, University of Stuttgart, Pfaffenwaldring 61, 70550 Stuttgart, Germany \\ ${ }^{2}$ Department of Physical Geography and Geoecology, Faculty of Science, Charles University in Prague, Albertov 6, \\ 12843 Prague 2, Czech Republic \\ ${ }^{3}$ Fachhochschule Stuttgart - Hochschule für Technik, Schellingstr. 24, 70174 Stuttgart, Germany
}

\begin{abstract}
A methodology for automated objective circulation pattern (CP) definition and classification is presented based on optimized fuzzy rules. The main goal of the method is to provide a basis (daily classified CPs) for downscaling of precipitation and temperature, which can be done by means of downscaling models with parameters depending on the CP. The CPs are defined using 500 or $700 \mathrm{hPa}$ geopotential height anomalies. Fuzzy rules are defined by the position of high- and lowpressure anomalies. The fuzzy rules are obtained automatically using an optimization of the performance of the classification. For precipitation, the performance of the classification is measured by rainfall frequencies and rainfall amounts conditioned on the CP. So the task is to define wet or dry CPs. For temperature, the deviation from the average long-term annual cycle is used. In this way warm or cold CPs are identified. The performance of the CPs is validated using a split-sampling approach. The presented method produces physically realistic CP definitions. With the help of these definitions the observed (historical) pressure fields can be classified as shown in 2 case studies for regions with different climate conditions: Central Europe (Germany) and the Eastern Mediterranean (Greece).
\end{abstract}

KEY WORDS: Circulation-pattern classification - Downscaling - Precipitation - Temperature · Fuzzy sets

\section{INTRODUCTION}

Especially because of the need to deal with future climate scenarios, much attention has been given to the problem of downscaling surface climate behavior from large-scale atmospheric circulation. Due to the high non-linearity and influence of local factors present in the atmospheric system, it is sometimes difficult to describe the relationship between atmospheric circulation and surface climate using a deterministic approach. However, from a statistical point of view there is evidence that the surface climate variables depend on large-scale atmospheric circulation. For example, Bürger (1958), Yoshino (1975) and Lamb (1977) proved that changes in atmospheric circulation affect precipitation. The quantification of the compli- cated non-linear relationship can be described with the help of circulation patterns.

There are several possibilities for downscaling, which form 2 main groups: dynamical downscaling and empirical downscaling. In the case of dynamical downscaling nested regional climate models (Giorgi \& Mearns 1991) are used to simulate subgrid scale features. The advantage of this method is that it delivers meteorologically consistent variables. However the uncertainty related to this method, and the nonuniqueness of the solution, is generally not taken into account. Empirical downscaling methods are based on local observations. These methods can generate a large number of realisations - thus the assessment of the uncertainty of the prediction is possible. Further local details which cannot be reflected by the dynami- 
cal models are considered in these methods. Empirical downscaling can be done by using either regression techniques or conditional-probability approaches. The regression method defines the relationship between the large-scale and local information by means of an explicit function (Wilks 1989, Kilsby et al. 1998, Pilling et al. 1998). The form of the function is usually selected so that the parameters can be estimated without major numerical difficulties. The explanatory variables are often selected using a trial-and-error procedure. The other empirical techniques use an intermediate step. The large-scale information is first classified using empirical, statistical or other methods. Then the downscaling is done by using stochastic models, with parameters dependent on the circulation pattern (CP) types. In this case the non-linearity of the downscaling is captured by the CPs, each of them having a specific relationship with the surface variables. The main motivation of the presented method is to provide an objective basis (day-by-day classified CPs) for downscaling models with parameters depending on the CP. The methodology of these models and their applications are not discussed in this paper. The model for downscaling of precipitation was presented in Bárdossy \& Plate (1992). Bárdossy \& Mierlo (2000) described the temperature downscaling model. However, the advantage of conditioning the downscaling on CPs is that the CPs characterize the atmospheric circulation on a large (continental) scale.

In CP classification techniques, 2 main groups of methods can be distinguished (Yarnal 1984, 1993). The first type of method is subjective classification. The advantage of this method is that the knowledge and experience of meteorologists is fully used in the classification. Major disadvantages are that the results cannot be reproduced and that this method can only be applied for certain geographical regions. Many subjective classifications have been developed for various regions with different scales: Baur et al. (1944) and Hess \& Brezowsky (1969) for Central Europe, Lamb (1972) for the British Isles, Maheras $(1988,1989)$ for Greece, Dzerdzeevskii (1968) for the extratropical latitudes of the Northern Hemisphere, and Krick (1943) and Elliott (1949) for the United States. The second type of CP-classification method is represented by objective techniques. They are based on automated algorithms operating on selected datasets, and they allow fast classification, which is necessary especially for climate-change scenarios. The objective-classification methods include $k$-means clustering (Wilson et al. 1992), a method based on physical quantities (Jenkinson \& Collison 1977); fuzzy classification, based on subjectively defined rules (Bárdossy et al. 1995); principal-component clustering (Goodess \& Palutikof 1998), principal-component analysis coupled with k-means clustering (Bogárdi et al. 1994); and neuralnetwork methods (Cawley \& Dorling 1996). A comparison of the Lamb subjective-classification and objective-classification schemes was performed by Jones et al. (1993).

The precipitation and temperature characteristics of CPs from most of the above-mentioned CP classification methods are studied 'ex post'. The mean precipitation behavior conditioned on the CPs is determined after the classification. The same holds true for temperature. The objective of the classification method presented in this paper is to define CPs so that they explain the variability of local surface climate variables (precipitation, temperature) in a locally specific functional form. Therefore the CPs explain the dependence between the large-scale atmospheric circulation and the surface climate.

The presented classification method is automated, fuzzy rule based and takes surface climate variables into account. The data used are daily 700 and $500 \mathrm{hPa}$ elevations, daily precipitation totals, and daily temperatures for 9 stations in Germany and 21 stations in Greece. In the case of Germany, the mean daily temperatures are used, whereas for Greece the daily temperature maxima are taken into account. These represent the natural variability quite well. This is also the highest time resolution available for large scales.

\section{METHODOLOGY}

\subsection{Classification method}

The classification method used is the fuzzy-rulebased classification. It is based on the concept of fuzzy sets (Zadeh 1965), which enables one to deal with imprecise statements. The classification consists of 3 steps: (1) data transformation; (2) definition of the fuzzy rules; and (3) classification of observed data. The classification is carried out using normalized pressure anomalies $g(i, t)$ of the daily geopotential height data ( $i$ stands for the gridpoint and $t$ for the day). The pressure data used are obtained from the NMC gridpoint data set for different windows over Europe with a grid resolution of $5^{\circ} \times 5^{\circ}$.

The procedure for fuzzy-rule-based classification is described in Bárdossy et al. (1995). Here only a brief description is given. Every CP is described with a fuzzy rule $k$ represented by a vector $v(k)=\left(v(1)^{(k)} \ldots v(n)^{(k)}\right)$, where $n$ is the number of gridpoints for which the airpressure data are available. The $v(i)^{(k)}$ are the indices of the membership function corresponding to the selected locations. Five possible classes of membership functions $v$ of the rule premises appear to be adequate according to the normalized geopotential height val- 
ues. The membership functions were defined as triangular (subscript $T$ ) fuzzy numbers: $V=1$, very low: $(-\infty,-1,-0.2)_{\mathrm{T}} ; v=2$, medium low: $(-1.4,-0.6,0)_{\mathrm{T}} ; v=3$, medium high: $(0,0.6,1.4)_{T i} v=4$, very high: $(0.2,1,+\infty)_{T i}$ and $v=5$, the membership function is the constant 1 .

The membership function of the triangular fuzzy number $(a, b, c)_{\mathrm{T}}$ is defined as:

$$
\mu(g)= \begin{cases}0 & \text { if } g<a \\ \frac{g-a}{b-a} & \text { if } a \leq g<b \\ \frac{g-c}{b-c} & \text { if } b \leq g<c \\ 0 & \text { if } g>c\end{cases}
$$

The fifth possibility was introduced to allow any possible geopotential height anomalies for those locations that have no influence on the circulation pattern. The location and number of such gridpoints depend on the class to be described. Usually most gridpoints belong to this class, and only characteristic ones are assigned to other classes. The location of these gridpoints might vary for different CPs.

For the data classification, the membership grades of the normal height anomalies were computed. For a given time $t$ and location $i$ the membership grade corresponding to rule $k$ is defined as

$$
\mu(i, k)=\mu_{v(i)}(k)(g(i, t))
$$

These membership values are combined to calculate the degree of fulfilment $D O F$ of the rule:

$$
\operatorname{DOF}(k, t)=\prod_{l=1}^{4}\left(\frac{1}{N\left(v(i)^{(k)}=l\right)} \sum_{v(i)^{(k)}=l} \mu(i, k)^{P_{l}}\right)^{\frac{1}{P_{l}}}
$$

where $N$ is the number of gridpoints classified by class $l_{\text {, }}$ and $P_{1} \geq 1$ is the parameter which allows one to emphasize the influence of selected classes on the $D O F$. The $k$ for which $\operatorname{DOF}(k, t)$ is maximal is selected as CP for day $t$.

The problem with this classification method is how to assess the rule vectors. A subjective definition of the rules requires good knowledge of the local meteorological conditions. This expertise is often not available. Another possibility, presented here, is the assessment of the rules using optimization.

\subsection{Performance measures}

In order to find the best possible rules for the description of local precipitation behavior, the performance of the classification has to be defined. Three types of objective functions can be introduced to measure the performance of the classification with regard to surface climate variables (precipitation and temperature).
The goal of the optimization for the description of precipitation is to achieve a set of CPs which explain the variability of precipitation behavior as much as possible. It is intended to identify both very wet or very dry conditions. Two types of objective functions were defined. The first deals with the probability of precipitation on a given day. By considering the threshold $\vartheta$ for the daily precipitation amount, the general definition of the first objective function can be given as:

$$
O_{1}(\vartheta)=\sum_{i=1}^{S} \sqrt{\frac{1}{T} \sum_{t=1}^{T}\left(p(C P(t))_{i}-\bar{p}_{i}\right)^{2}}
$$

Here $S$ is number of stations, $T$ is number of days, $p(\mathrm{CP}(t))_{i}$ is the probability of precipitation exceeding the threshold $\vartheta$ on a day with given CP at $\operatorname{Stn} i_{i} \bar{p}_{i}$ is the probability of a day with precipitation exceeding $\vartheta$ for all days without classification and within the time period $T$.

For the precipitation amounts the following objective function is defined:

$$
O_{2}=\sum_{i=1}^{S} \frac{1}{T} \sum_{t=1}^{T}\left|\ln \left(\frac{z(C P(t))_{i}}{\bar{z}_{i}}\right)\right|
$$

Here $z(\mathrm{CP}(t))_{i}$ is the mean precipitation amount on a day with a given $\mathrm{CP}$ at $\operatorname{Stn} i$ and $\bar{z}_{i}$ is the mean daily precipitation without classification at the same station. Higher values of $O_{1}(\vartheta)$ and $O_{2}$ indicate a better classification. It is possible to combine more objective functions by taking a weighted sum:

$$
O=a_{1} O_{1}\left(\vartheta_{1}\right)+\ldots+a_{n} O_{1}\left(\vartheta_{n}\right)+a_{n+1} O_{2}
$$

where $a_{1} \ldots a_{n+1}$ are weights. The weights are selected in order to express the importance of the different objective functions and to correct for the different ranges of the functions.

A reasonable choice, used in this research, is to use 2 thresholds for $O_{1}$ : the first threshold being $\vartheta_{1}=0.1 \mathrm{~mm}$ $\mathrm{d}^{-1}$, taking all days with precipitation into account, and the second $\left(\vartheta_{2}\right)$ defining the days with high precipitation amounts $\left(>10 \mathrm{~mm} \mathrm{~d}^{-1}\right)$. The overall objective is then defined as follows:

$$
O=a_{1} O_{1}\left(\vartheta_{1}\right)+a_{2} O_{1}\left(\vartheta_{2}\right)+a_{3} O_{2}
$$

The objective function of the temperature-oriented classification procedure is to obtain $\mathrm{CPs}$ which explain deviations from the mean (CPs unconditioned) annual cycle as much as possible, i.e. to define some very cold and some very warm CPs within one classification. The objective function to be maximized is defined as:

$$
O_{3}=\sum_{i=1}^{S} \sum_{j=1}^{N} \sum_{k=1}^{D}\left(T_{i j k}-T_{i k}\right)^{2}
$$

Here $N$ is number of CPs, $D$ is number of days in the year, $T_{i j k}$ is average daily CP-conditioned temperature 
at $\operatorname{Stn} i$, for CP $j$ and on Day $k_{\text {, and }} T_{i k}$ is average daily unconditioned temperature at $\operatorname{Stn} i$ and on Day $k$.

Two optimization constraints were introduced. The first defines the maximal number of pixels belonging to specific classes (e.g. very low or medium high pressure) within one $\mathrm{CP}$, whereas the second constraint disables the existence of extreme pressure gradients. These constraints ensure not only physically realistic $\mathrm{CP}$ definitions, but also faster convergence of the optimization procedure.

\subsection{Optimization algorithm}

The objective of the optimization procedure is to find such fuzzy rules for which the optimisation criterion is maximal. This means that the problem can be defined as combinatorial. Due to a given number of fuzzy rules (CPs), it is necessary to consider that each rule has a given number of terms (gridpoints), depending on the size of the pressure window, and that for each gridpoint 1 from 5 states (fuzzy numbers) can be defined. Because of a large number of possible combinations, it is unfortunately not possible to compute the objective function for each combination systematically. The number of all combinations depends on the size of the pressure window and number of CPs to be optimized. In the case studies presented in this paper it is approximately $10^{1000}$. Therefore, consideration of all the possibilities to find the best is impossible. A simulated annealing algorithm (Aarts \& Korst 1989) is used as an optimization procedure. For the fixed number of rules the algorithm can be briefly described as follows:

(0) Initialize the rules randomly and evaluate the performance $O$

(1) Set the initial 'annealing temperature' to $q_{0}$

(2) Select a rule $k$ randomly

(3) Select a location $i$ randomly

(4) Select a class $V^{*}$ randomly

(5) If $v(i)^{(k)}=V^{*}$, return to step 2

(6) Set $v(i)^{(k)}=V^{*}$ and perform the classification

(7) Calculate performance $O^{*}$ for the new rules

(8) If $O^{*}>O$, then accept the change (9) If $O^{*} \leq O$, then with probability $\exp \left(\frac{O-O^{*}}{q_{s}}\right)$
accept the change

(10) If the change is accepted, replace $O$ by $O^{*}$

(11) Repeat steps 2 to $10 \mathrm{M}$ times

(12) Decrease the 'annealing temperature' by setting $q_{s+1}<q_{s}$

(13) Repeat steps 2 to 12 until the portion of accepted changes becomes smaller then a predefined threshold

The initial annealing temperature $q_{0}$ is selected so that 50 to $80 \%$ of the attempted changes are accepted. During the first iterations the program adjusts it so that the above condition is fulfilled. The reason for this choice is to allow strong departures from the initial rules. The number of attempted changes at a given annealing temperature $M$ should be at least as many as the number of arguments multiplied by the number of rules. The algorithm makes it possible to accept negative changes. The willingness to accept these changes depends on the 'annealing temperature', which is decreased during the optimization procedure. It is worth mentioning that the initial classification does not influence the appearance of the resulting optimized CPs at all. The optimization process adjusts any initial classification to an optimum solution.

\subsection{Validation of CP classifications}

A split sampling approach was used for the process of CP optimization and validation. The formulae used as optimization criteria can also be applied as measures of the classification quality. However, despite the optimization already carried out, it is still necessary to evaluate the overall quality of the optimized classification, e.g. in comparison to completely different classification techniques. Assessment of a new classification can either be a comparison to another, for example, subjective classification, or an internal classification, with respect to the quality of hydrological conclusions that can be drawn from the membership of $1 \mathrm{CP}$ within the classification. Parameters to evaluate the performance of precipitation-oriented classifications are based on the following quantities: $H H$ (in \%) -relative occurrence frequency of a CP for a given time period; $p(\mathrm{CP}(t))($ in $\%)$ - probability of precipitation on a day with a given $\mathrm{CP} ; \mathrm{A} / \mathrm{HH}$-wetness index, the ratio of the percentage of annual precipitation total and the precipitation total for a given $\mathrm{CP}$ and its appearance rate (high values indicate 'wet' $\mathrm{CPs}$ ); $m$ (in $\mathrm{mm}$ ) mean precipitation total on a wet day for a given $\mathrm{CP}$; and $s$ (in $\mathrm{mm}$ ) - standard deviation of precipitation total on a wet day for a given CP.

Any classification that defines probability $p(\mathrm{CP}(t))$ and mean $z(\mathrm{CP}(t))$ of precipitation on a selected station for a single day $t$ referring to the classification of the same day can be measured by the indices identical to the objective functions $\mathrm{O}_{1}$ and $\mathrm{O}_{2}$.

Both indices increase with quality. To allow a seasonal difference of behavior for the classes (e.g. dry in summer and wet in winter), the indices are usually calculated for all seasons separately. Defining threshold values for precipitation guarantees that the optimized classification is good, especially for extreme rainfall events.

The quality of the classification based on temperature data is determined by using the index: 


$$
I_{T}=\frac{1}{N} \sum_{j=1}^{N} \frac{1}{D} \sum_{k=1}^{D}\left|T_{j k}-T_{k}\right|
$$

Here $I_{\mathrm{T}}$ is the average daily absolute difference in ${ }^{\circ} \mathrm{C}$ for all $\mathrm{CPs}$ between $\mathrm{CP}$-conditioned temperature cycles and the unconditioned cycle for all CPs and 1 station, $T_{j k}$ is the average daily CP-conditioned temperature for $\mathrm{CP} j$ and Day $k$, and $T_{k}$ is the average daily unconditioned temperature on Day $k$. Higher values of $I_{\mathrm{T}}$ indicate a better classification.

\section{APPLICATION}

The above described methodology was applied in 2 different regions from the climate point of view: Central Europe (Germany) and Eastern Mediterranean (Greece). For the CP optimization the calibration period 1980-89 and validation period 1970-79 were selected. For each case study, $18 \mathrm{CP}$ optimizations, subsequent classifications and validations were performed. The goal was to assess the influence of geopotential surfaces $(700 \mathrm{hPa}, 500 \mathrm{hPa}$ and sea-level pressure) as well as the window size from which to take the pressure values. Another question was how many CPs should be generated to best describe rainfall or temperature characteristics in an area. Using too few CPs leads to a loss of information, since their behavior only represents averaged weather conditions. Too many CPs result in very low occurrence frequencies, which make statistical investigation impossible. Also, it was of interest to see in what extent the form of the objective functions influenced the validation results.

\subsection{Results for Central Europe (Germany)}

For CP classification, which explains the precipitation and temperature variability, it was found that the $500 \mathrm{hPa}$ data in the window $35-65^{\circ} \mathrm{N}, 15^{\circ} \mathrm{W}-40^{\circ} \mathrm{E}$ provided the best results. The optimal number of CPs was found to be 12, both for precipitation- and temperature-based optimizations. Daily precipitation totals or daily mean temperatures from 9 Germany-wide distributed stations were used for both calibration and the validation procedure.

\subsubsection{Precipitation-based classification}

For the precipitation-based optimization, a threshold of $\vartheta_{1}=0.1 \mathrm{~mm}$ and $\vartheta_{2}=10 \mathrm{~mm}$ in the objective function (Eq. 7) was used. Table 1 presents CPs and precipitation characteristics for the precipitation station in Stuttgart. The average occurrence frequency of most
CPs is approximately the same in each season. An exception is CP 3, for example, with $4.6 \%$ of occurrence in summer and $11.3 \%$ in winter. Generally it holds that in every season the wettest (considering the annual average) CPs are wet and the driest CPs are dry. If the annual wetness index is close to 1 , the wet/dry character of the CP may vary from season to season. For example CP 2 is wet in summer (wetness index 1.71), yet it contributes relatively little to precipitation in winter (wetness index 0.63).

Fig. 1 shows the distributions of the mean (1970-79) normalized $500 \mathrm{hPa}$ geopotential height anomalies for the wettest and driest CPs. CP 1 is the most frequent $\mathrm{CP}$ and dominates throughout the year, having an average annual frequency of about $40 \%$. At the same time it is the driest $\mathrm{CP}$, with the lowest precipitation probability $(25.6 \%)$, the lowest mean wet-day amount $(1.1 \mathrm{~mm})$, and the lowest wetness index $(0.63)$. The map shows that CP 1 is characterized by a pronounced high-pressure anomaly east of the British Isles, which causes a weak air movement and transport of dry air
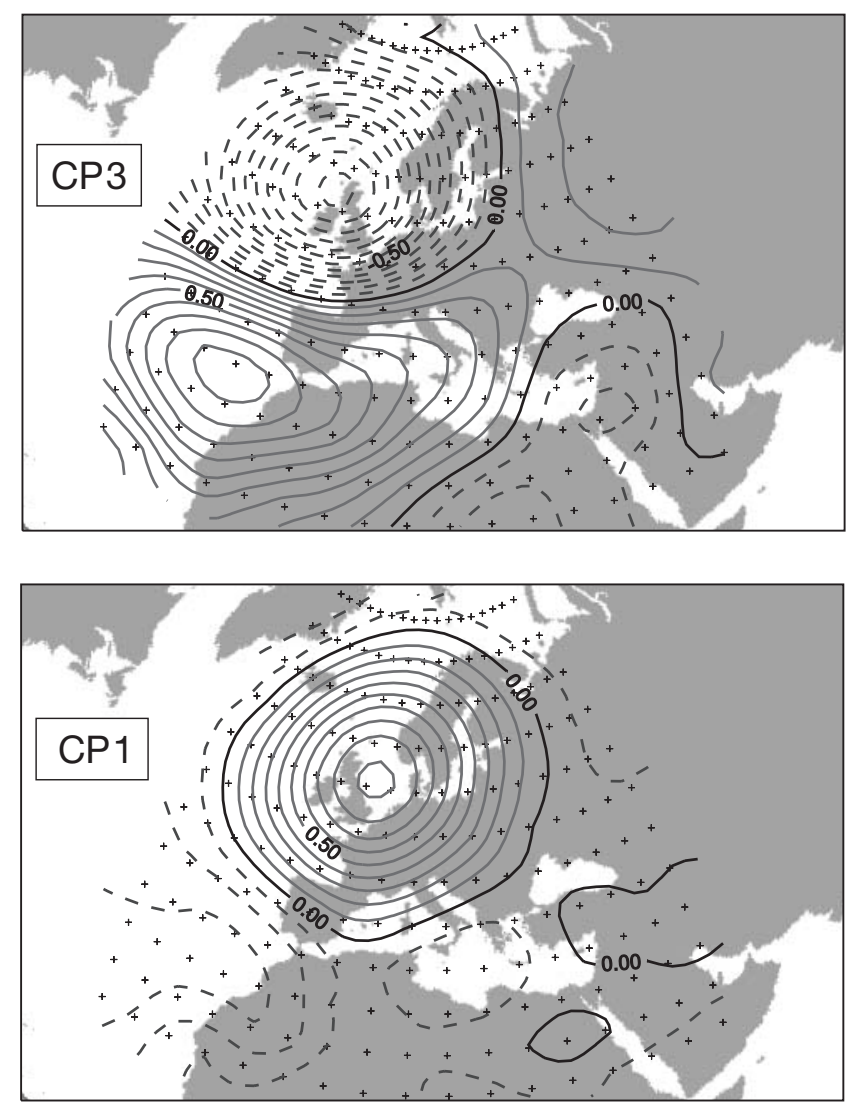

Fig. 1. Mean normalized distributions of $500 \mathrm{hPa}$ geopotential height of 1 wet (above) and 1 dry (bottom) circulation pattern (CP), averaged over 1970-79. (CPs are precipitationoptimized over 1980-89 with $500 \mathrm{hPa}$ data and 9 stations in Germany) 
Table 1. CP and precipitation characteristics at Stn Stuttgart for precipitation. Values are averaged over the validation period 1970-79. (CP optimization: $500 \mathrm{hPa}$ data, $12 \mathrm{CPs}$, precipitation-optimized, 1980-89, 9 stations in Germany)

\begin{tabular}{|c|c|c|c|c|c|c|c|c|c|c|c|c|}
\hline $\mathrm{CP}:$ & 1 & 2 & 3 & 4 & 5 & 6 & 7 & 8 & 9 & 10 & 11 & 12 \\
\hline \multicolumn{13}{|c|}{ Precipitation probability (\%) } \\
\hline Spring & 26.9 & 46.2 & 67.1 & 60.9 & 36.4 & 33.3 & 71.4 & 68.0 & 63.5 & 43.4 & 57.8 & 48.0 \\
\hline Summer & 30.5 & 56.0 & 64.3 & 38.5 & 39.3 & 14.9 & 75.0 & 67.7 & 65.5 & 29.2 & 71.1 & 56.7 \\
\hline Fall & 18.4 & 42.2 & 74.0 & 53.6 & 48.4 & 26.1 & 56.3 & 76.2 & 68.4 & 34.7 & 66.7 & 73.3 \\
\hline Winter & 26.3 & 30.3 & 62.7 & 54.2 & 41.3 & 33.3 & 46.2 & 82.4 & 70.6 & 69.2 & 32.0 & 73.3 \\
\hline Year & 25.6 & 41.5 & 66.9 & 51.5 & 41.3 & 26.2 & 61.5 & 73.2 & 66.5 & 41.7 & 58.5 & 62.0 \\
\hline \multicolumn{13}{|c|}{ Mean wet-day amount (mm) } \\
\hline Spring & 1.0 & 2.5 & 2.6 & 2.0 & 1.5 & 2.4 & 0.8 & 2.1 & 2.6 & 0.9 & 2.2 & 1.5 \\
\hline Summer & 2.1 & 4.3 & 3.9 & 0.7 & 2.0 & 1.3 & 3.0 & 3.3 & 3.6 & 1.7 & 3.1 & 3.2 \\
\hline Fall & 0.7 & 1.5 & 3.4 & 2.2 & 1.4 & 1.1 & 0.9 & 3.4 & 2.1 & 1.8 & 2.8 & 2.0 \\
\hline Winter & 0.5 & 0.7 & 2.3 & 1.3 & 1.3 & 1.1 & 1.3 & 1.8 & 2.8 & 1.8 & 0.4 & 1.3 \\
\hline Year & 1.1 & 2.0 & 2.9 & 1.5 & 1.5 & 1.5 & 1.6 & 2.8 & 2.8 & 1.5 & 2.2 & 2.2 \\
\hline \multicolumn{13}{|c|}{ Standard deviation of wet-day amount (mm) } \\
\hline Spring & 3.3 & 10.3 & 4.0 & 3.2 & 3.1 & 6.2 & 0.8 & 3.1 & 5.6 & 1.6 & 3.3 & 2.8 \\
\hline Summer & 7.2 & 9.3 & 4.5 & 1.5 & 3.8 & 4.5 & 4.8 & 5.1 & 6.7 & 4.4 & 5.2 & 5.3 \\
\hline Fall & 2.3 & 4.5 & 5.4 & 3.3 & 3.0 & 3.1 & 1.2 & 4.8 & 3.2 & 3.7 & 3.9 & 3.5 \\
\hline Winter & 1.4 & 2.2 & 3.4 & 2.3 & 2.9 & 2.8 & 2.1 & 2.1 & 4.7 & 2.8 & 0.8 & 2.0 \\
\hline Year & 4.4 & 7.3 & 4.3 & 2.7 & 3.2 & 4.5 & 3.0 & 4.1 & 5.4 & 3.4 & 3.9 & 3.9 \\
\hline \multicolumn{13}{|c|}{ CP occurrence frequency (\%) } \\
\hline Spring & 35.2 & 11.3 & 7.9 & 2.5 & 3.6 & 4.9 & 0.8 & 10.9 & 8.0 & 5.8 & 4.9 & 2.7 \\
\hline Summer & 45.2 & 5.4 & 4.6 & 2.8 & 3.0 & 5.1 & 1.7 & 10.4 & 6.0 & 7.1 & 4.1 & 3.3 \\
\hline Fall & 40.5 & 7.0 & 8.0 & 3.1 & 3.4 & 5.1 & 1.8 & 13.4 & 4.2 & 5.4 & 3.0 & 3.3 \\
\hline Winter & 39.7 & 12.1 & 11.3 & 2.7 & 5.1 & 3.3 & 1.4 & 8.2 & 5.7 & 4.3 & 2.8 & 1.7 \\
\hline Year & 40.2 & 9.0 & 7.9 & 2.8 & 3.8 & 4.6 & 1.4 & 10.7 & 6.0 & 5.6 & 3.7 & 2.7 \\
\hline \multicolumn{13}{|c|}{ CP wetness index (precipitation contribution / occurrence frequency) } \\
\hline Spring & 0.56 & 1.42 & 1.52 & 1.15 & 0.89 & 1.36 & 0.45 & 1.21 & 1.51 & 0.54 & 1.25 & 0.88 \\
\hline Summer & 0.84 & 1.71 & 1.56 & 0.26 & 0.81 & 0.51 & 1.22 & 1.34 & 1.46 & 0.67 & 1.24 & 1.30 \\
\hline Fall & 0.41 & 0.93 & 2.07 & 1.31 & 0.83 & 0.67 & 0.53 & 2.07 & 1.28 & 1.10 & 1.70 & 1.23 \\
\hline Winter & 0.42 & 0.63 & 2.04 & 1.20 & 1.14 & 0.97 & 1.16 & 1.63 & 2.50 & 1.64 & 0.34 & 1.13 \\
\hline Year & 0.63 & 1.12 & 1.65 & 0.88 & 0.86 & 0.85 & 0.93 & 1.58 & 1.61 & 0.88 & 1.27 & 1.23 \\
\hline
\end{tabular}

masses from northeastern Europe to central Europe. $\mathrm{CP} 3$ is a typical wet $\mathrm{CP}$ which has the second highest precipitation probability $(66.9 \%)$, highest mean wetday amount $(2.9 \mathrm{~mm})$, and highest wetness index (1.65). Fig. 1 shows that CP 3 is characterized by a typical negative pressure anomaly north of the British Isles and a positive anomaly over the eastern Atlantic. This distribution of pressure anomalies causes the typical west cyclonic transport of wet, ocean air mass from the North Atlantic to Central Europe. The maps of pressure anomalies show that the presented automated classification method produces physically realistic results.

Wetness indices (precipitation contribution/occurrence frequency) for every $\mathrm{CP}$, every season (and annual cycle) and all 9 stations used for calibration were computed. As in case of Stn Stuttgart, the wettest CP is $\mathrm{CP} 3$ and the driest $\mathrm{CP}$ is $\mathrm{CP} 1$. Fig. 2 shows that both the above-described CPs have the same (wet or dry) character at all stations. Also in the case of other CPs, it holds that wet CPs are wet and dry CPs are dry for almost all stations simultaneously. The spatially homo- geneous character of wetness index patterns is reflected in the relatively low values of the coefficient of variation $(\mathrm{CV})$ calculated from all stations and for a selected CP (ranging to 0.08 for CP 9 and 0.29 for $\mathrm{CP}$ $2)$. The negative correlation $(-0.47)$ between the average wetness index and the CV indicates that the spatial variability of the wetness index is greater for dry CPs. This is caused by the fact that the wet CPs have a west or north cyclonic character, which causes precipitation events covering large areas. However, for dry CPs, local precipitation events (especially convective rainfalls in summer) are typical.

\subsubsection{Temperature-based classification}

For the temperature-based optimization, the objective function (Eq. 8) was used. Twelve temperatureoptimized CPs were classified; they were in general different from the 12 precipitation-optimized CPs. The mean normalized $500 \mathrm{hPa}$ geopotential height anomalies for the warmest and the coldest $\mathrm{CP}$ with the cor- 

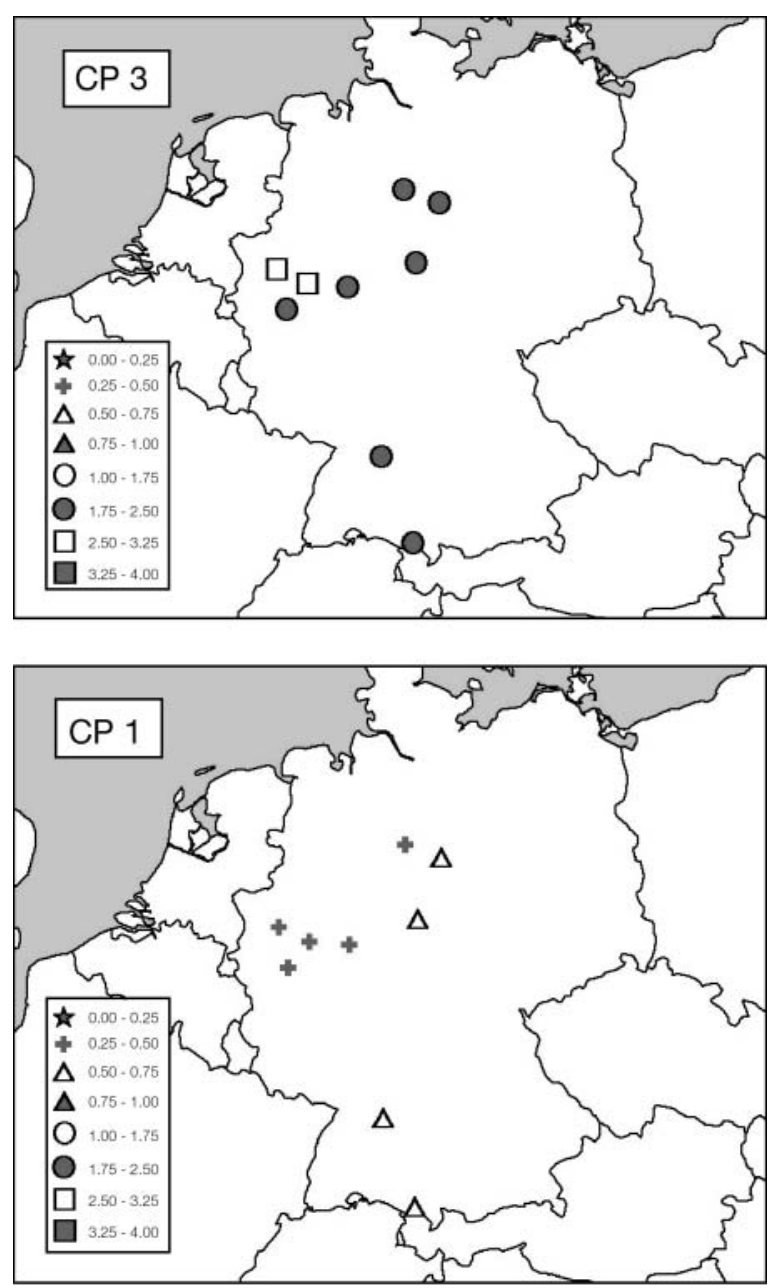

Fig. 2. Spatial variability of yearly wetness index for 1 wet (above) and 1 dry (bottom) CP for 9 stations in Germany, 1970-79. (CPs are precipitation-optimized over 1980-89 with $500 \mathrm{hPa}$ data and 9 stations in Germany)

responding mean annual temperature cycle are presented in Figs. 3 \& 4. CP 5 is the warmest CP, having an average absolute daily difference from the unconditioned temperature cycle of $3.12^{\circ} \mathrm{C}$. Its average annual frequency of occurrence is about $9.5 \%$. Central Europe lies between a pronounced high-pressure anomaly over Italy and a low-pressure anomaly positioned northwest of the British Isles. This distribution of pressure anomalies causes an intensive transport of warm air masses from the south and southwest directions. A typical cold $\mathrm{CP}$ is $\mathrm{CP} 11\left(I_{\mathrm{T}}=3.24^{\circ} \mathrm{C}\right)$ with average occurrence frequency $12.7 \%$. It is characterized by a positive pressure anomaly southwest of Iceland and a negative anomaly over northern Italy, which causes a transport of cold air masses from the Baltic Sea and Scandinavia to central Europe. Figs. 3 \& 4 show that the described CPs have either a warm or a cold character during the whole year.

\subsection{Results for the Eastern Mediterranean (Greece)}

For the Greek climate the extreme difference in precipitation between summer and winter is typical. Also great differences of precipitation amounts occur at different stations on the same day. While one station might measure high rainfall amounts, another might measure no rain at all. A great advantage of the automated classification optimization is that it takes each individual station's behavior into account.

Precipitation and temperature data from 21 climate stations evenly spread over Greece were taken into account for calibration and validation purposes. For CP classification, which explains the precipitation and temperature variability, the $700 \mathrm{hPa}$ pressure data in the window $20-65^{\circ} \mathrm{N}, 20^{\circ} \mathrm{W}-50^{\circ} \mathrm{E}$ yielded the best results. It was found that 12 is the optimal number of CPs.

The result of the validation of many different optimizations with different weightings is that the precipitation-based optimization with emphasis on extreme precipitation (5 times higher weight for $5 \mathrm{~mm}$ threshold
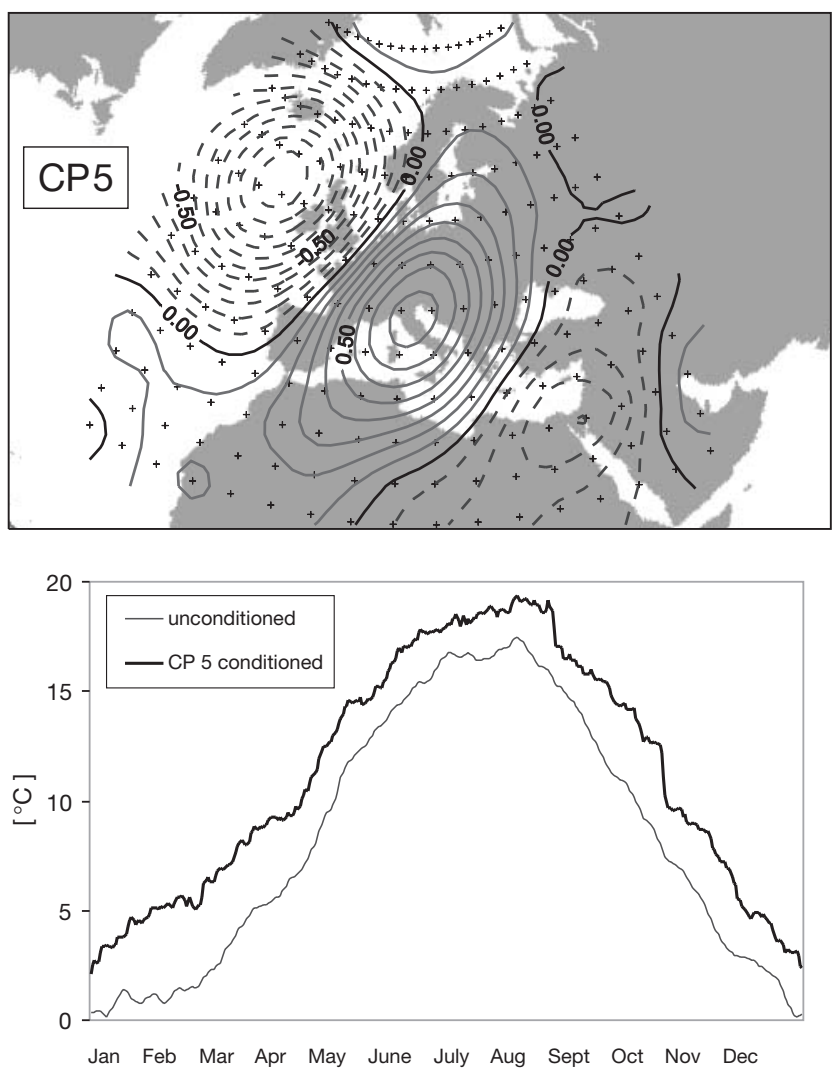

Fig. 3. Mean (1970-79) normalized distributions of $500 \mathrm{hPa}$ geopotential height anomalies (above) of 1 warm CP with the corresponding temperature cycle (bottom). (CPs are temperature-optimized over 1980-89 with $500 \mathrm{hPa}$ data and 9 stations in Germany) 

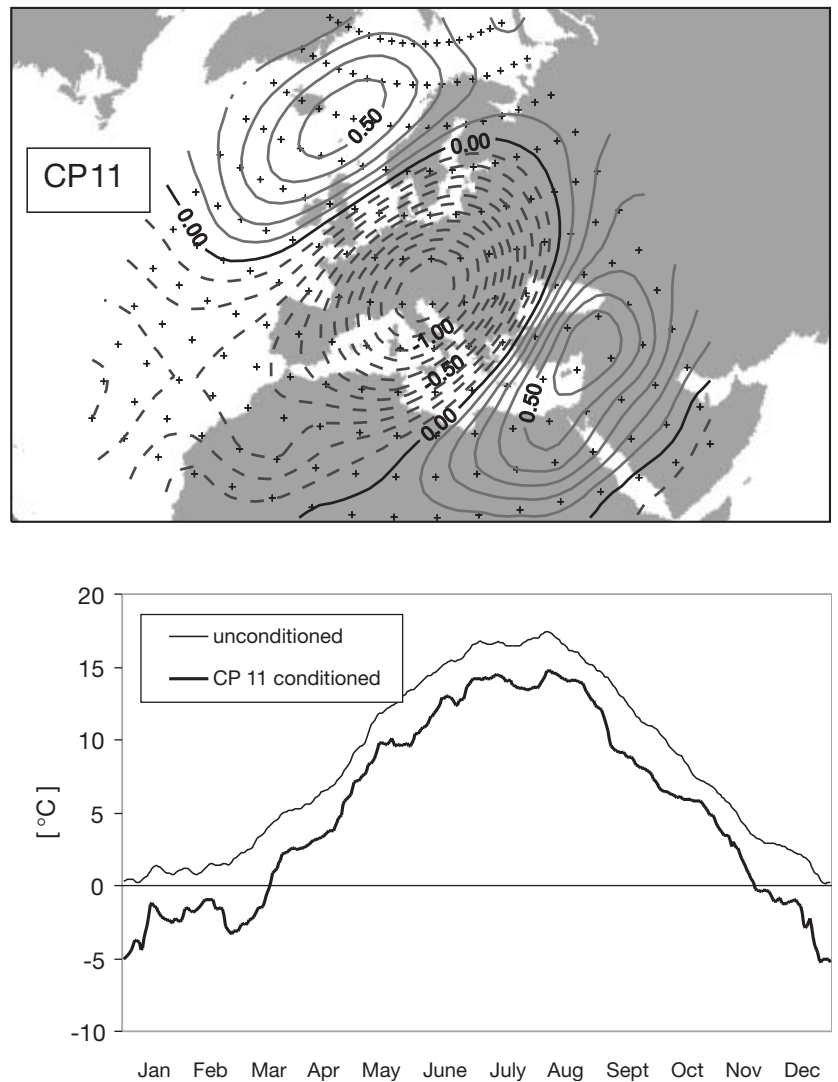

Fig. 4. Mean (1970-79) normalized distributions of $500 \mathrm{hPa}$ geopotential height anomalies (above) of 1 cold CP with the corresponding temperature cycle (bottom). (CPs are temperature-optimized over 1980-89 with $500 \mathrm{hPa}$ data and 9 stations in Germany)

than for $0 \mathrm{~mm}$ ) yielded very good results both for precipitation and temperature validation. Therefore the $\mathrm{CP}$ classification both for precipitation and temperature interpretations was based on the CP definitions obtained from the optimization mentioned above. Similar results for precipitation and temperature validations reveal the strong coupling of precipitation and temperature under the Greek climate conditions, where a decrease in temperature is mostly accompanied by precipitation. It has to be considered that this coupling is also probably caused by the fact that the temperature data used for this investigation are daily maxima.

\subsubsection{Relationship between CPs and precipitation}

$\mathrm{CP}$ and precipitation statistics for the precipitation station Athens, which is located approximately in the middle of the investigated area and has a typical annual cycle of precipitation with very little precipitation in summer and higher precipitation in winter, are shown in Table 2. The table shows that CPs 6 and 7 do not contribute to summer precipitation at all, because the precipitation probability is zero. As in the case of the German study, the occurrence frequency of most CPs remains approximately the same in each season. Whereas other CPs have a frequency of between 2 and $10 \%$, CP 9 is exceptionally frequent, occurring in approximately $30 \%$ of the days in each season. For Athens, very wet and very dry CPs have a wet or dry character in every season. CPs which are not pronounced from the annual wetness index point of view vary their wet and dry character seasonally, e.g. CP 7 is wet in winter (wetness index 1.63) and absolutely dry in summer.

The distributions of mean (1970-79) normalized $700 \mathrm{hPa}$ pressure anomalies for the wettest and the driest CP are presented in Fig. 5. The wettest CP is CP 1 (wetness index 3.62). It is characterized by the center of the low-pressure anomalies positioned near Greece. In the case of the driest CP (CP 9 with wet-
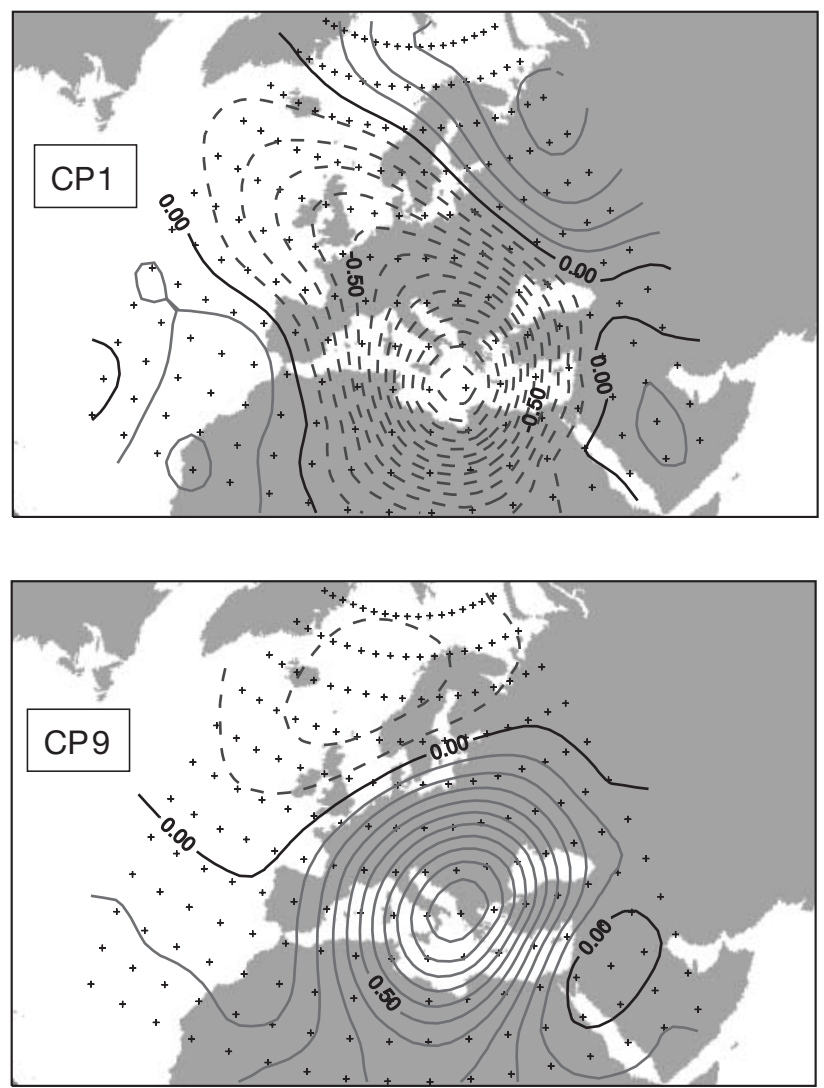

Fig. 5. Mean normalized distributions of $700 \mathrm{hPa}$ geopotential height anomalies of 1 wet (above) and 1 dry (bottom) $\mathrm{CP}$, averaged over 1970-79. (CPs are extreme precipitation optimized over 1980-89 with $700 \mathrm{hPa}$ data and 21 stations in Greece) 
Table 2. CP characteristics at Stn Athens for precipitation. Values averaged over the validation period 1970-79. (CP optimization: $700 \mathrm{hPa}$ data, 12 CPs, extreme precipitation-optimized, 1980-89, 21 stations in Greece)

\begin{tabular}{|c|c|c|c|c|c|c|c|c|c|c|c|c|}
\hline $\mathrm{CP}:$ & 1 & 2 & 3 & 4 & 5 & 6 & 7 & 8 & 9 & 10 & 11 & 12 \\
\hline \multicolumn{13}{|c|}{ Precipitation probability (\%) } \\
\hline Spring & 47.73 & 40.79 & 21.57 & 18.31 & 27.91 & 10.00 & 14.00 & 23.53 & 6.60 & 32.93 & 9.59 & 24.14 \\
\hline Summer & 17.50 & 12.31 & 3.23 & 4.00 & 7.27 & 0.00 & 0.00 & 3.13 & 1.08 & 11.90 & 2.63 & 5.00 \\
\hline Fall & 48.53 & 21.62 & 22.45 & 23.61 & 25.58 & 9.09 & 26.09 & 15.15 & 2.72 & 52.63 & 7.27 & 29.03 \\
\hline Winter & 61.54 & 44.09 & 24.32 & 33.33 & 32.50 & 50.00 & 35.29 & 27.50 & 14.34 & 55.36 & 19.05 & 48.15 \\
\hline Year & 44.34 & 31.17 & 18.60 & 19.00 & 22.10 & 18.75 & 17.32 & 17.99 & 6.08 & 35.13 & 10.07 & 24.41 \\
\hline \multicolumn{13}{|c|}{ Mean wet-day amount (mm) } \\
\hline Spring & 2.96 & 1.01 & 1.22 & 0.43 & 1.13 & 0.63 & 0.30 & 0.64 & 0.13 & 1.68 & 0.15 & 0.70 \\
\hline Summer & 0.69 & 0.36 & 0.04 & 0.02 & 0.58 & 0.00 & 0.00 & 0.05 & 0.02 & 0.43 & 0.12 & 0.35 \\
\hline Fall & 5.30 & 1.59 & 0.62 & 1.46 & 3.85 & 0.45 & 0.82 & 0.69 & 0.26 & 3.65 & 0.55 & 0.73 \\
\hline Winter & 6.38 & 2.29 & 1.25 & 1.43 & 0.68 & 2.39 & 3.04 & 0.81 & 0.55 & 3.97 & 0.64 & 2.56 \\
\hline Year & 3.84 & 1.40 & 0.77 & 0.80 & 1.51 & 0.95 & 0.87 & 0.57 & 0.24 & 2.16 & 0.36 & 0.99 \\
\hline \multicolumn{13}{|c|}{ Standard deviation of wet-day amount (mm) } \\
\hline Spring & 6.92 & 2.82 & 6.65 & 1.68 & 2.57 & 2.15 & 1.03 & 2.11 & 0.84 & 4.45 & 0.76 & 1.72 \\
\hline Summer & 2.64 & 1.37 & 0.28 & 0.10 & 3.27 & 0.00 & 0.00 & 0.28 & 0.27 & 2.03 & 0.78 & 2.06 \\
\hline Fall & 10.19 & 7.91 & 1.69 & 4.22 & 11.92 & 1.51 & 2.66 & 2.90 & 3.86 & 6.72 & 2.91 & 2.02 \\
\hline Winter & 12.19 & 6.13 & 4.50 & 4.23 & 2.13 & 4.82 & 7.63 & 3.04 & 2.35 & 6.16 & 2.17 & 5.85 \\
\hline Year & 9.04 & 5.38 & 3.77 & 3.07 & 6.38 & 2.98 & 3.75 & 2.39 & 2.33 & 5.07 & 1.82 & 3.27 \\
\hline \multicolumn{13}{|c|}{ CP occurrence frequency $(\%)$} \\
\hline Spring & 9.57 & 8.26 & 5.54 & 7.72 & 4.67 & 2.17 & 5.43 & 3.70 & 31.30 & 8.91 & 7.93 & 3.15 \\
\hline Summer & 8.70 & 7.07 & 6.74 & 8.15 & 5.98 & 1.63 & 5.33 & 3.48 & 30.33 & 9.13 & 8.26 & 4.35 \\
\hline Fall & 7.47 & 8.13 & 10.77 & 7.91 & 4.73 & 1.21 & 5.05 & 3.63 & 32.31 & 6.26 & 6.04 & 3.41 \\
\hline Winter & 10.11 & 10.33 & 8.22 & 6.67 & 4.44 & 2.00 & 3.78 & 4.44 & 30.22 & 6.22 & 9.33 & 3.00 \\
\hline Year & 8.95 & 8.43 & 7.80 & 7.64 & 4.96 & 1.75 & 4.90 & 3.81 & 31.05 & 7.64 & 7.89 & 3.48 \\
\hline \multicolumn{13}{|c|}{ CP wetness index (precipitation contribution / occurrence frequency) } \\
\hline Spring & 3.71 & 1.26 & 1.53 & 0.54 & 1.42 & 0.80 & 0.38 & 0.80 & 0.16 & 2.10 & 0.18 & 0.87 \\
\hline Summer & 3.50 & 1.84 & 0.22 & 0.09 & 2.93 & 0.00 & 0.00 & 0.25 & 0.12 & 2.16 & 0.61 & 1.76 \\
\hline Fall & 3.77 & 1.13 & 0.44 & 1.04 & 2.73 & 0.32 & 0.58 & 0.49 & 0.18 & 2.59 & 0.39 & 0.52 \\
\hline Winter & 3.42 & 1.23 & 0.67 & 0.76 & 0.36 & 1.28 & 1.63 & 0.43 & 0.29 & 2.12 & 0.34 & 1.37 \\
\hline Year & 3.62 & 1.32 & 0.72 & 0.75 & 1.42 & 0.89 & 0.82 & 0.53 & 0.22 & 2.04 & 0.34 & 0.93 \\
\hline
\end{tabular}

ness index 0.22), the pronounced high-pressure anomaly has its center directly over Greece. The Greek pressure anomalies maps can also be interpreted.

Fig. 6 shows that both of the above-described wet and dry CPs have a wet and dry character over the whole region. However, generally the CPs are not as spatially homogeneous as they were for Germany. The wetness index for one CP may differ considerably for different stations. Examples are CPs 2 and 3 (Fig. 7). Whereas CP 2 is dry for the northwest part of Greece, it is at the same time wet for the southeast. In the case of CP 3, the situation is reversed.

The spatially inhomogeneous character of the wetness index patterns for one CP is reflected in high values of CV for all stations. It ranges from 0.20 for CP 1 to 0.66 for CP 3, whereas in Germany CV ranged from 0.08 to 0.29 . Similar to Germany, the negative correlation coefficient $(-0.37)$ between the average wetness index and $\mathrm{CV}$ indicates that the spatial variability of the wetness index is greater for dry CPs and lower for wet CPs. Again the reason could be that local convec- tive rainfalls are probably more often coupled with dry CPs (high-pressure anomalies over or near Greece) than with wet ones.

\subsubsection{Relationship between CPs and temperature}

The mean (1970-79) normalized 700 hPa geopotential height anomalies for the warmest and the coldest $\mathrm{CP}$ with the corresponding mean annual cycle of daily temperature maxima are shown in Figs. 8 \& 9 . The warmest CP is CP 11 (occurrence frequency $7.89 \%$ ) with average $I_{\mathrm{T}}=2.28$. It is especially warm in winter $\left(I_{\mathrm{T}}=2.81\right)$. It is characterized by the movement of warm air from the southwest direction over Greece, which is caused by a positive pressure anomaly over the Eastern Mediterranean and a negative anomaly over Central Europe. CP 11 is at the same time the second driest CP. The position of pressure anomalies is reversed in the case of $\mathrm{CP} 2$, which is the coldest $\mathrm{CP}$, with a frequency of $8.43 \%$ and $I_{\mathrm{T}}=$ 2.41 . 

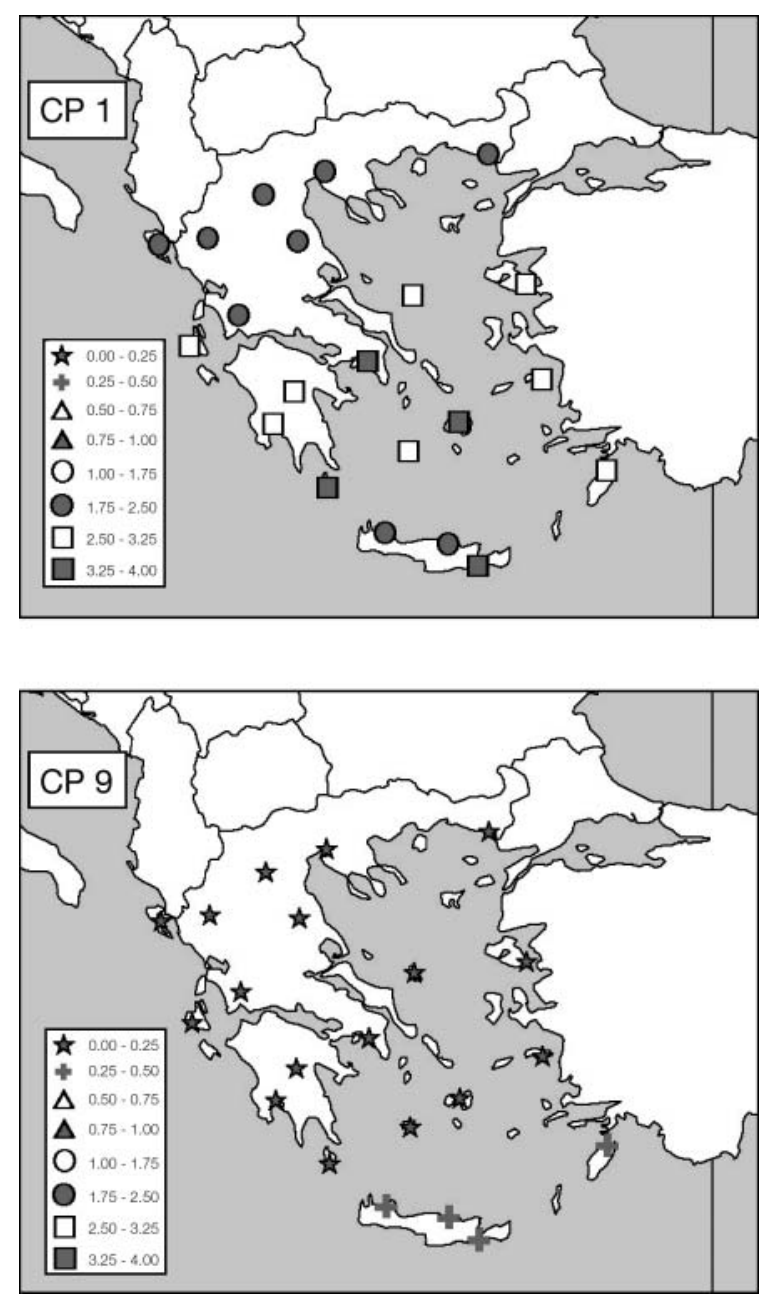

Fig. 6. Spatial variability of yearly wetness index for 1 wet (above) and 1 dry (bottom) CP for 21 stations in Greece, 1970-79. (CP are extreme-precipitation-optimized over 1980-89 with $700 \mathrm{hPa}$ data and 21 stations in Greece)

\section{DISCUSSION AND CONCLUSIONS}

An automated and objective method of CP classification is presented in the paper. It is based on a fuzzy rules approach, which enables one to deal with verbal descriptions of geopotential heights and pressure data anomalies in a mathematical way. The goal of the classification aimed at explanation of precipitation variability is to define CPs which bring wet or dry weather into the specified region. Temperature-oriented classification defines warm and cold CPs. In order to find the best set of CPs, a simulated annealing algorithm was used which makes it possible to solve a complicated optimization problem connected with the definitions of CPs. Two applications of the method (for Germany and Greece) show that the method produces physically
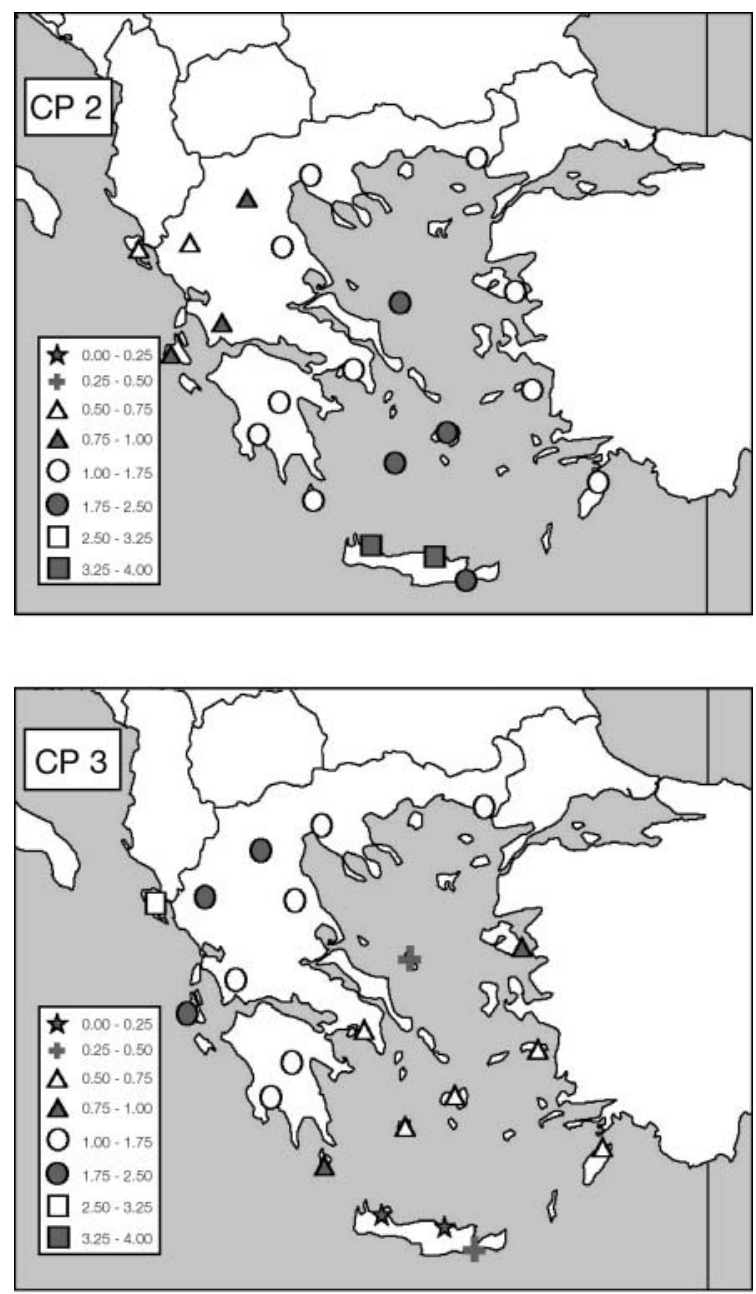

Fig. 7. Spatial variability of yearly wetness index for 2 heterogeneous CPs for 21 stations in Greece, 1970-79. (CPs are extreme-precipitation-optimized over 1980-89 with $700 \mathrm{hPa}$ data and 21 stations in Greece)

realistic CP definitions. This is evident from the presented maps of geopotential heights anomalies.

In the next research step, the method will be used for downscaling of precipitation and temperature by means of models with parameters depending on the CPs. The advantage of the CPs' conditioning is that the CPs reflect the atmospheric circulation on large scales. It would be also of interest to use more variables (such as precipitation and temperature) at the same time for the CP classification. Also, more pressure fields (e.g. $500 \mathrm{hPa}, 700 \mathrm{hPa}$, sea-level pressure or thickness of the 500-700 hPa layer) could be taken into account.

The CP definitions will also be used to classify outputs from global circulation models (GCMs). The changes in frequencies and transition probabilities among CPs will be compared to historical data. It 

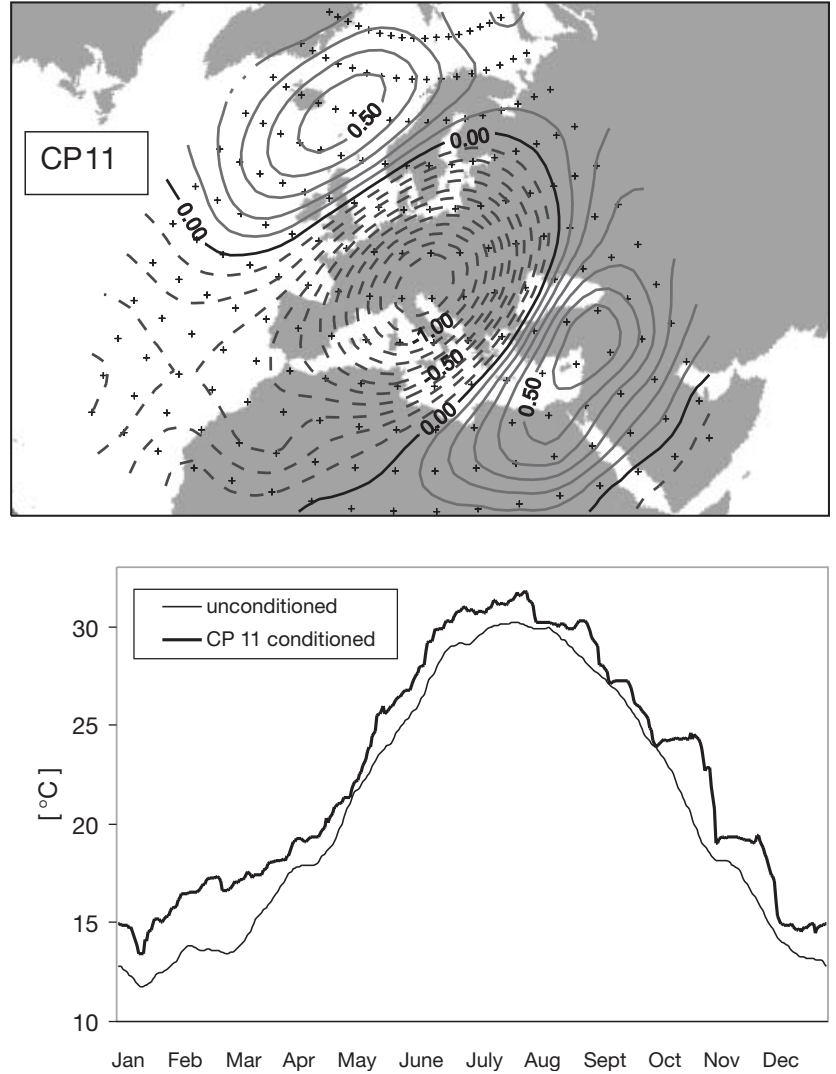

Fig. 8. Mean (1970-79) normalized distributions of $700 \mathrm{hPa}$ geopotential height anomalies (above) of 1 warm CP with the corresponding cycle of daily temperature maxima (bottom). (CPs are extreme precipitation optimized over 1980-89 with $700 \mathrm{hPa}$ data and 21 stations in Greece)

would be valuable to compare the series of observed CPs with those from GCM control runs $\left(1 \times \mathrm{CO}_{2}\right)$. This is one way in which the reliability of GCM outputs could be tested. Downscaling the precipitation and temperature from GCM climate-change scenarios $(2 \times$ $\mathrm{CO}_{2}$ ) will be performed in order to assess the changes in local climate due to the changes in atmospheric circulation.

Acknowledgements. The authors are grateful for the funding of this work by DGXII of the European Commission. The work was part of the EU Research Project 'Atmospheric circulation classification and regional downscaling (ACCORD)' (ENV4CT97-0530).

\section{LITERATURE CITED}

Aarts E, Korst J (1989) Simulated annealing and boltzmann machines: a stochastic approach to combinatorial optimization and neural computing. John Wiley \& Sons, Chichester

Bárdossy A, Mierlo JMC (2000) Regional precipitation and temperature scenarios for climate change. Hydrol Sci J 45(4):559-575
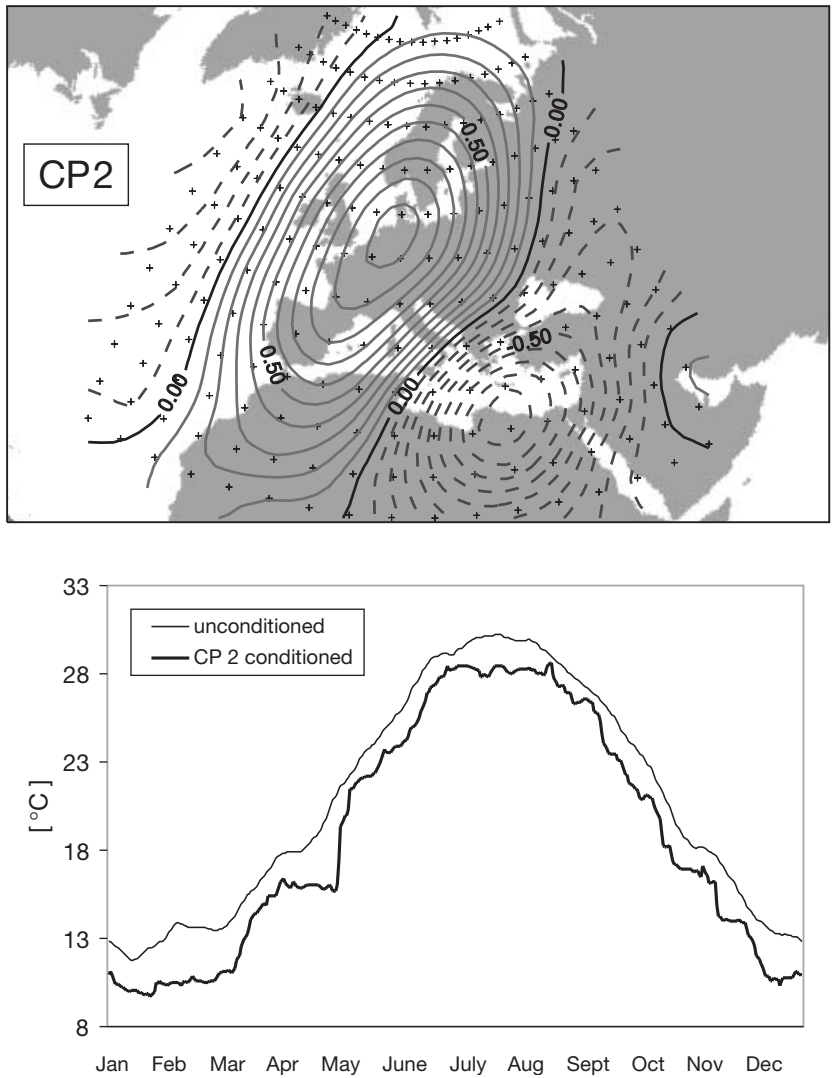

Fig. 9. Mean (1970-79) normalized distributions of $700 \mathrm{hPa}$ geopotential height anomalies (above) of 1 cold $\mathrm{CP}$ with the corresponding cycle of daily temperature maxima (bottom). (CPs are extreme precipitation optimized over 1980-89 with $700 \mathrm{hPa}$ data and 21 stations in Greece)

Bárdossy A, Plate EJ (1992) Space-time model of daily rainfall using atmospheric circulation patterns. Water Resour Res 28(5):1247-1259

Bárdossy A, Duckstein L, Bogárdi I (1995) Fuzzy rule—based classification of atmospheric circulation patterns. Int J Climatol 15:1087-1097

Baur F, Hess P, Nagel H (1944) Kalendar der Grosswetterlagen Europas 1881-1939. Deutscher Wetterdienst, Bad Homburg

Bogárdi I, Matyasovszky I, Bárdossy A, Duckstein L (1994) A hydroclimatological model of areal drought. J Hydrol 153: 245-264

Bürger K (1958) Zur Klimatologie der Großwetterlagen. Ber Dtsch Wetterdienstes 45, Vol 6. Selbstverlag des Deutschen Wetterdienstes, Offenbach am Main

Cawley GC, Dorling SR (1996) Reproducing a subjective classification scheme for atmospheric circulation patterns over the United Kingdom using a neural network. In: Proceedings of the International Conference on Artificial Neural Networks (ICANN-96). Springer, Bochum, p 281-286

Dzerdzeevskii BL (1968) Circulation mechanism in the atmosphere of the northern hemisphere in the twentieth century. Institute for Geography, Soviet Academy of Sciences, Moscow (in Russian). [Goedecke R (translator), Berryman BF (ed), University of Wisconsin Press, Madison, WI, 1970]

Elliott RD (1949) The weather types of N. America. Weatherwise $2: 15-18,40-43,64-67,86-88,110-113,136-138$ 
Giorgi F, Mearns LO (1991) Approaches to the simulation of regional climate change. A review. Rev Geophys 29:191-216

Goodess CM, Palutikof JP (1998) Development of daily rainfall scenarios for southeast Spain using a circulation-type approach to downscaling. Int J Climatol 18:1051-1083

Hess P, Brezowsky H (1969) Katalog der Großwetterlagen Europas. 2. Neu bearbaitete und ergänzte Aufl Berichte des Deutschen Wetterdienstes 113, Selbstverlag des Deutschen Wetterdienstes, Offenbach am Main

Jenkinson AF, Collison FP (1977) An initial climatology of gales over the North Sea. Synoptic Climatology Branch Memorandum No. 62, Meteorological Office, Bracknell

Jones PD, Hulme M, Briffa KR (1993) A comparison of Lamb circulation types with an objective classification scheme. Int J Climatol 13:665-663

Kilsby CG, Coepertwait PSP, O'Connel PE, Jones PD (1998) Predicting rainfall statistics in England and Wales using atmospheric circulation variables. Int $\mathrm{J}$ Climatol 18: 523-539

Krick IP (1943) Synoptic weather types of North America. Californian Institute of Technology, Pasadena, CA

Lamb HH (1972) British Isles weather types and a register of daily sequence of circulation patterns, 1861-1971. Geophysical Memoirs 110, Meteorology Office, London

Lamb HH (1977) Climate, present, past and future, Vol 2, Climatic history and the future. Methuen, London

Maheras P (1988) The synoptic weather types and objective

Editorial responsibility: Hans von Storch, Geesthacht, Germany delimitation of the winter period in Greece. Weather 43: $40-45$

Maheras P (1989) Delimitation of the summer-dry period in Greece according to the frequency of weather-types. Theor Appl Climatol 39:171-176

Pilling C, Wilby RL, Jones JAA (1998) Downscaling of catchment hydrometeorology from GCM output using airflow indices: Upper Wye catchment, Plynlimon, upland Wales. In: Wheater $\mathrm{H}$, Kirby $\mathrm{C}$ (eds) Global hydrological processes: ecological and hydrological interactions. John Wiley \& Sons, Chichester, p 191-208

Wilks DS (1989) Statistical specification of local surface weather elements from large-scale information. Theor Appl Climatol 40:119-134

Wilson LL, Lettenmaier DP, Skyllingstad E (1992) A hierarchical stochastic model of large scale atmospheric circulation patterns and multiple station daily rainfall. J Geophys Res 97(3):2791-2809

Yarnal B (1984) A procedure for the classification of synoptic weather maps from gridded atmospheric surface pressure data. Comput Geosci 10:394-410

Yarnal B (1993) Synoptic climatology in environmental analysis. Studies in Climatology Series, Belhaven Press, London

Yoshino MM (1975) Climate in a small area. University of Tokyo Press, Tokyo

Zadeh LA (1965) Fuzzy sets. Information Control 8(3): $338-353$

Submitted: March 21, 2001; Accepted: May 1, 2002

Proofs received from author(s): October 16, 2002 